\title{
An Integrated Model of Compliance with COVID-19 Prescriptions: Instrumental, Normative, and Affective Factors Associated with Health-Protective Behaviors
}

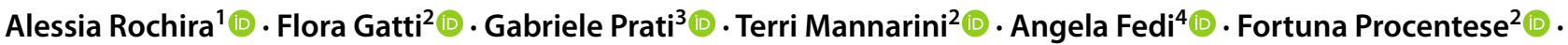

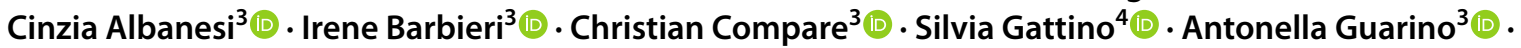 \\ Daniela Marzana ${ }^{5}(1) \cdot$ lana Tzankova ${ }^{3}(1) \cdot$ Giovanni Aresi $^{5}(\mathbb{0}$
}

Accepted: 19 December 2021 / Published online: 3 January 2022

(c) International Society of Behavioral Medicine 2022

\begin{abstract}
Background The efficacy of public measures for reducing the transmission of the COVID-19 infection relies on citizens' voluntary adherence with prescribed actions. Drawing on prior literature about compliant behavior, this study aimed to identify factors associated with people engagement in health-protective behaviors by including a conjoint complement of instrumental/self-oriented, normative/community-based, and affective variables.

Method A cross-sectional study involving a non-representative sample of 4045 Italian citizens was carried out during the first stage of the pandemic (April-May 2020). Variables associated with health-protective behaviors were perceived personal and societal concerns and perceived effectiveness of the institutional response to the outbreak (instrumental dimensions), and family and friends perceived norms and sense of community responsibility (normative dimensions). Two negative emotions (anxiety and fear) were included as mediators between personal and societal concerns and outcome behaviors.

Results Results showed the importance of both self-interest and community-based factors. Indeed, self-interest concerns, family perceived norms, and sense of community responsibility were significant predictors of people's decisions to engage in health-protective behaviors.

Conclusions The research findings show that compliance with public health prescriptions is a multimodal phenomenon and integrating self-interest and community-based factors can offer a better understanding of people's decision to engage in health-protective behaviors. Further, this study unveils that a shared sense of community is effective in encouraging adherence to recommended behaviors so as behavioral changes can be sustained by targeting the recommendations not only on risk minimization for oneself but also on the allocation of personal responsibility toward the belonging community.
\end{abstract}

\section{Introduction}

Alessia Rochira

alessia.rochira@unisalento.it

1 Department of History, Society and Human Studies, Laboratory of Applied Psychology, University of Salento, Via di Valesio, 73100 Lecce, Italy

2 Department of Humanities, University of Naples Federico II, via Porta di Massa 1, Napoli 80133, Italy

3 Department of Psychology, University of Bologna, Piazza Aldo Moro 90, Cesena 47521, Italy

4 Department of Psychology, University of Torino, via Verdi 10, Torino 10124, Italy

5 Psychology Department, Università Cattolica del Sacro Cuore, Largo Gemelli 1, Milano 20123, Italy
In early 2020, the World Health Organization (WHO) declared the Chinese outbreak of SARS-Cov-2 to be a global pandemic and issued guidelines for national governments to reduce the spread of the contagion [1]. It was soon clear, however, that no healthcare system was able to cope with the emergency without widespread adoption by the population of behaviors that protect from the transmission of the virus. Indeed, it is crucial to understand what encourages people to adhere to recommended behaviors and contribute to overcome this and future health emergencies [2].

Italy represents an interesting case study to understand the dynamics underlying people's compliance with mandatory public health instructions. First, among Western countries, the Italian national government imposed a strict 
nationwide stay-at-home order starting on the 8th of March 2020. The lockdown lasted 2 months and was partially eased on the 4th of May. Following WHO guidelines [3], the Italian government and health authorities also issued to the general population recommendations of protective behaviors to reduce the transmission of the virus. Recommendations included a range of behaviors that can be distinguished into preventative (i.e., hygiene behaviors such as hand washing, cleaning surfaces with alcohol-based disinfectants, sneezing and/or coughing in a tissue or elbow), and avoidant (i.e., physical distancing such as avoiding crowded places, home working and distance learning) conducts [4]. In this regard, Alegria, Fleszar-Pavlović, Ngo, et al. [5] differentiated among COVID-19 related risk behaviors-such as having houseguests and shopping-and increased protective behaviors-for instance, hand washing. In specifics, examples of recommended preventative behaviors in Italy were washing hands often using soaps or alcohol-based solvents, not touching eyes, nose, and mouth with hands, sneezing and/or coughing in a tissue or elbow, using the face masks; in addition, examples of recommended avoidant behaviors were avoiding close contact with people, maintaining an interpersonal distance of at least one meter, avoided crowded places, leaving the house and traveling only for valid and urgent reasons.

In the field of psychological and social sciences, when examining what sustains people's decisions to comply with prescriptions and engage in the advised behaviors, two general perspectives can be found: one considers instrumental or self-interest concerns as key factors [6]; the other focuses on the normative or community-based influences coming from the social environment [7]. By analyzing data collected from a large sample of Italian adults during the 2020 March-May COVID-19 outbreak, this paper examines the conjoint contribution of these two theoretical perspectives in understanding factors associated with people's adherence to behaviors required to reduce virus transmission.

\section{The Instrumental/Self-interest Perspective}

According to the instrumental/self-interest standpoint that sourced from the field of criminology [6], individuals are self-interested subjects who seek to maximize benefits and minimize losses; the decision to engage in law-abiding behaviors depends on a cost-benefit analysis: people respect the law because they fear the consequences of its violation $[8,9]$. However, there is evidence that to comply with the law people need to perceive that the risk of the sanction (i.e., getting caught) is high, and the associated cost for themselves will be significant $[10,11]$. As far as it concerns compliance toward protective measures during health emergencies, self-interest considerations can be understood not only as of the perceived risk for oneself health but also as the perceived risk for oneself wealth due to the negative impact of the health emergency at collective level (e.g., economics, healthcare system, social security, etc.).

In health psychology research, the individual cost has been mainly understood as perceived personal vulnerability to disease. Individuals are more prone to follow recommendations when they perceive a high risk of being infected [12, 13], of suffering harmful consequences [14] as well as when they believe that they have a certain degree of control over the risk of infection [15]. Concerns about being infected have been found to motivate individuals to carry out protective and avoidant behaviors during pandemics (for a qualitative review see [4]). More recently, it has been demonstrated that the perceived risk of being infected and experiencing harmful consequences are related to compliance with prescribed behaviors during the COVID-19 outbreak [16]. Risks perception for oneself safety cover the possibility not only of contracting the virus but also of suffering secondary risks created by the pandemic at collective level (e.g., economic downturn, unemployment, overload within the health system). In this regard, people were shown to be concerned about potential personal economic losses, global economic recession, and reduction of healthcare supplies [17]. Indeed, those who perceive that the pandemic poses a serious threat are more likely to follow prevention guidelines [18].

Together with these concerns, the belief that the use of protective behaviors can be effective to contrast the COVID-19 spread appeared to be associated with the decision to follow the formal recommendations [19]. Importantly, the belief that public authorities are trustworthy [20], and that the measures they adopted are appropriate/ efficacious to contrast the health emergency were proved to be related to people conformity [21]. For example, trust in government has been shown to be associated with the decision to follow social distancing in the aftermath of Ebola outbreak and H1N1 pandemic [22, 23]; overall, Van Bavel, Baicker, Boggio, et al. [24] highlighted that the hallmark of behavioral change during health emergencies relies on the active and voluntary cooperation of the population and suggested that trust in public institutions plays a pivotal role in supporting people compliance.

\section{The Normative/Community-Based Perspective}

This approach stresses the importance of shared norms and personal beliefs that respecting the law is the right thing to do in society [25]. Such beliefs are likely to be influenced by social identity dynamics, including shared norms [26]. Law-abiding behaviors and expectations of family members and significant others (e.g., friends) exert an influence 
over people's decision to adhere to the norms [27]. In other words, shared social identities contribute to shaping individual intention to play out compliant behaviors [28]. Adopting the prescribed behaviors is seen as a form of group engagement that is further fortified by perceptions of being fairly treated by the authority that creates and enforces the rules $[29,30]$.

During previous infectious diseases, greater perceptions that the adherence to the expected behaviors is valued by significant others and groups, such as family members, have been found to be related to individuals' decision to wear facemasks throughout the 2003 SARS surge in China [31]. Recent studies have extended these results to the current COVID-19 health emergency. In particular, both descriptive and injunctive norms have been found to predict behavioral intentions to behave repeatedly and consistently with public recommendations [32, 33].

References to shared norms are available in community contexts that nurture a sense of belonging and responsibility among members [34]. Feeling of personal responsibility toward the belonging community can induce individuals to take actions for its benefit [71] as long as the community is not seen only as a resource to meet personal needs and achieve personal rewards [35, 36]. Accordingly, engaging in health-protective behaviors is felt as a duty to act for the collective well-being and represents the right thing to do along with community standards (e.g., norms, beliefs, and values) that prescribe how to behave according to specific circumstances [37]. In sum, people take the decision to conform to institutional recommendations in the best interest of their community [38].

\section{The Role of the Emotional Responses in the Adoption of Health-Protective Behavior}

During health emergencies, individuals certainly suffer emotionally $[39,40]$, and there is no doubt that the psychological impact of the current COVID-19 pandemic is quite serious [41, 42]. Importantly, emotional responses can play a role in shaping people's adherence to prescriptions [4]. Despite there is agreement on the role of negative emotional responses, namely, anxiety and fear, in encouraging the engagement in protective behaviors during health emergencies $[16,43]$, these have received relatively little attention. Increased levels of anxiety and preoccupation have been associated with adherence to mandatory recommendations during the SARS outbreak and the spread of influenza H1N1 [15, 44, 45]. Further, Prati, Pietrantoni, and Zani [46] demonstrated that the affective response to pandemic influenza H1N1 2009 was a significant predictor of people's motivation to take precautionary measures.
In regards to the COVID-19 health emergency, studies investigating public response to official recommendations suggest that increasing levels of anxiety and worry can be associated with the tendency to engage in health-protective actions [16] and preventative behaviors [47]. Also, fear has been found to be associated with compliance with public health recommendations [43]. Indeed, negative emotions motivate individuals to disengage from health risky conducts $[48,49]$ and take risk-aversive actions.

Although the existing empirical evidence, the contribution of negative emotions associated with risk perceptions has to be further ascertained. There is agreement in the literature that cognitive and emotional processes interact in responding to threats posed by an illness [4]. Given that the choice to respect the law is based on a cost-benefit analysis, cognitive material could be more quickly accessed than affective material as the former habitually support behavioral decisions to comply with formal rules $[67,68]$ In the same, following appraisal theories, Prati, Pietrantoni, and Zani [46] argued that cognitive evaluations influenced affective responses toward health risks and demonstrated that the affective responses to pandemic influenza H1N1 2009 fully mediated the relationship between risk perception and the engagement in recommended behaviors. Indeed, based on the aforementioned theoretical and empirical premises, we hypothesized that the link between concerns and behaviors may well be indirect, and at least partly mediated by fear and anxiety.

\section{The Current Study}

Using data from a large sample of Italian adults collected during the 2020 March-May COVID-19 outbreak this study aims to test an integrated model of citizens' compliance with health measures. In specifics, it conjointly examines the contribution of the instrumental/self-interest and normative/ community-based approaches in understanding variables associated with people's adherence with behaviors recommended by national health authorities to reduce the SARS$\mathrm{CoV}-2$ virus transmission, namely, avoidant and protective preventative behaviors.

Study hypotheses were (see Fig. 1):

$\mathrm{H}_{1}$ Factors pertaining to the instrumental/self-interest perspective would be positively related to protective behaviors. That is, when individuals are concerned with the effects of the coronavirus pandemic (a) for their personal safety (e.g., personal costs) as well as (b) for the security of the society (e.g., social costs) and (c) perceive that the institutional response to the outbreak is effective, they are more likely to engage in both preventative and avoidant behaviors.

$\mathrm{H}_{2}$ The relationship between the concerns for personal safety and social security and the compliance with the 


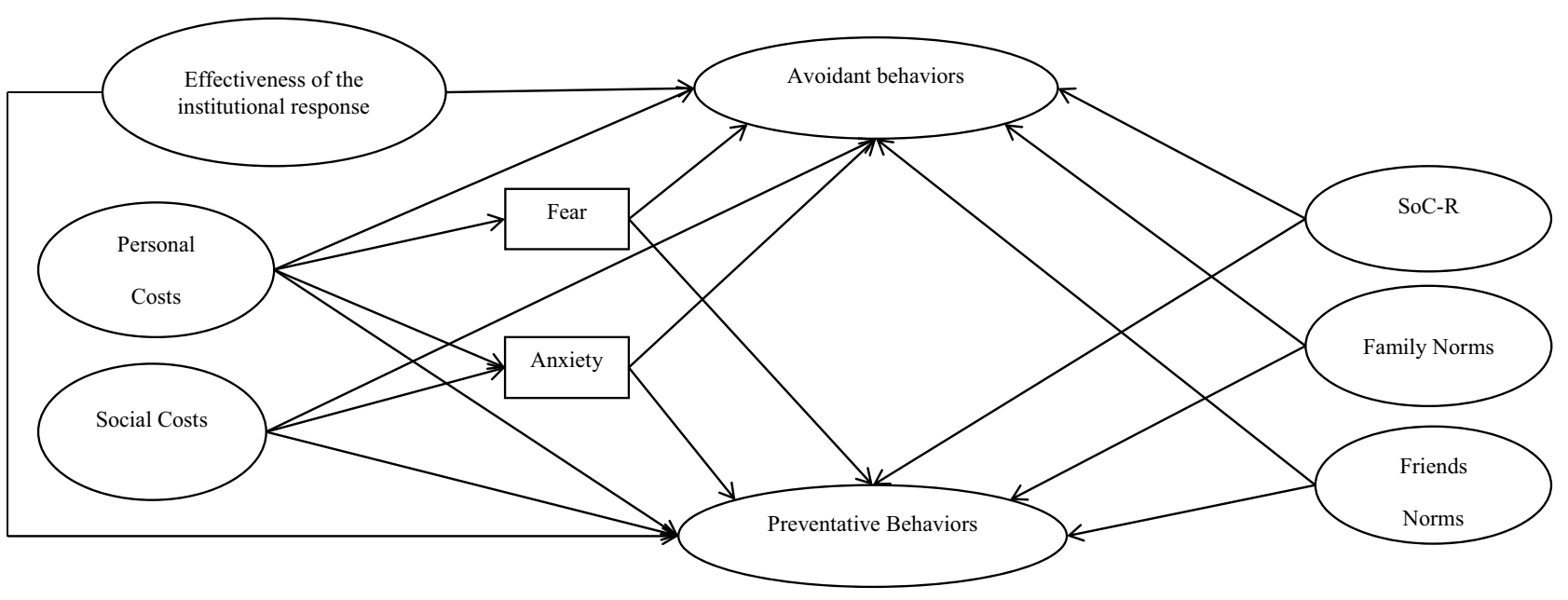

Instrumental/ Self-interested

Normative/Community-based Perspective

Fig. 1 Hypothesized theoretical model

recommended preventative and avoidant behaviors would be mediated by anxiety and fear engendered by the COVID19. In line with existing empirical evidence [46], individuals being more concerned with COVID-19-related consequences for their personal safety and for the security of the society (e.g., personal and social costs) are more likely to experience fear and anxiety with reference to the pandemic and in turn also more likely to adhere to the protective behaviors recommended by national health authorities. Precisely, individuals would be induced to adopt health-protective behaviors facing the perceived threats to their own and social safety as long as these perceptions engender negative affective responses, namely, anxiety and fear, that in turn could serve protective adaptive and functional purposes [16, 19, 50].

$\mathrm{H}_{3}$ Factors pertaining to the normative/community perspective would be positively related to both preventative and avoidant behaviors. That is, when individuals perceive that (d) family and (e) friends are following official recommendations and expect them to do the same, and (f) experience a great sense of community responsibility, they are more likely to perform preventative and avoidant behaviors.

Gender and age were included in the model as control variables.

\section{Method}

\section{Participants and Procedures}

Participants in the study were 4045 Italian citizens $(69.5 \%$ female). This study was the result of a collaborative effort by five Italian universities: the University of Bologna, University of Naples Federico II, University of Torino,
University of Salento, and Università Cattolica del Sacro Cuore. Because of the nationwide lockdown restrictions, each university research team recruited participants through direct contact via email or social networks in their respective geographic area. Adult participants were emailed a link to a survey (Qualtrics platform). People under the age of 18 were excluded. Local municipalities and community organizations were involved to disseminate the survey. A snowball sampling technique was used whereby respondents were asked to forward the survey link to others. Participants completed an online informed consent for taking part in the study. The e-form included information about the purpose of the research, the procedure to fill out the questionnaire and the approximate duration, the spontaneous nature of their participation, whom to contact for questions, and the right to withdraw from the questionnaire at any moment. Questionnaire completion took about $20 \mathrm{~min}$, and no incentives were offered to participants. Participants were not required to answer all questions. Data collection lasted two months, between the 12th of April and the 21st of May 2020. For this study, ethical approval has been obtained from the Human Research Ethics Committee at the University of Bologna.

Respondents were aged between 18 and $84(M=39.84$; $S D=14.27)$; two respondents chose not to disclose their age. Most of them live with their close relatives-e.g., nuclear family $(32.66 \%)$, parents $(27.09 \%)$, partner $(20.15 \%)$, children $(3.54 \%)$ - whereas only a small quota was in a cohabitation relationship (6.65\%) or lived alone (9.91\%). 32.38\% of the respondents had a high school diploma, $15.62 \%$ a bachelor's degree, $24.03 \%$ a master's degree, and $16 \%$ a post-degree title (e.g., post-graduate specialization, Ph.D.); only a few participants had a professional diploma (4.03\%) or held an education lower than secondary school $(7.94 \%)$. 
As of their occupation, $45.3 \%$ declared they were employees, $15.4 \%$ were self-employed, $2.8 \%$ were seasonal workers, $15.2 \%$ were students, and $0.8 \%$ were researchers; $7.4 \%$ were unemployed and $6.1 \%$ were retired; and $7 \%$ did not answer this question.

\section{Measures}

The questionnaire consisted of a socio-demographic section and the following measures.

\section{Protective Behaviors (Preventative and Avoidant Behaviors)}

Eight ad hoc items were developed to rate how often the respondents engage in preventative and avoidant protective behaviors, as recommended by the Italian government and health authorities [51]. Three items were pooled for protective behaviors (e.g., "wash your hands often with soap and water or using an alcohol-based gel") and five for avoidant behaviors (e.g., "avoid crowded places"). Format response asked for frequency on a 5 -point Likert scale $(1=$ never; $5=$ always $)$. The items both showed satisfactory reliability (respectively, $\alpha=0.69$ and $\alpha=0.67$ ).

\section{Sense of Community Responsibility}

The Italian version [52] of the Sense of Community Responsibility scale [35] was used. It comprises six items rated on a 5-point Likert scale from 1 "completely disagree" to 5 "completely agree" (e.g., "It is easy for me to put aside my own agenda in favor of the greater good of my community") $(\alpha=0.86)$.

\section{Family and Friends Norms}

Four ad hoc items were developed (e.g., "my family/friends encourage(s) me to implement the recommended protective behaviors"; "my family/friends engage(s) in the recommended protective behaviors on a regular basis") on a 1 "completely disagree" to 5 "completely agree" 5 -point Likert scale (family norms, $\alpha=0.76$; friends norms, $\alpha=0.79$ ).

\section{Personal Costs}

Five ad hoc items were used to assess respondents' concerns for personal safety (e.g., "the possibility of being infected") on a 1 "nothing" to 5 "at all" 5-point Likert scale $(\alpha=0.70)$.

\section{Social Costs}

Three ad hoc items were adopted to rate the participant's concerns for the impact of COVID-19 pandemic on society (e.g., "the possibility of economic recession due to the downtime"). Items were rated on a 5-point Likert-type scale ranging from 1 "nothing" to 5 "at all" $(\alpha=0.78)$.

\section{Negative Emotions}

Two dichotomous items assessed participants' affective response to the COVID-19 pandemic. Respondents were asked "thinking about the current situation in Italy, what are your feelings?". The answers were fear and anxiety.

\section{Effectiveness of the Institutional Response}

Respondents were requested to rate how much institutions were implementing effective measures in contrasting the outbreak of the COVID-19 pandemic on a 1 "nothing" to 5 "at all" 5-point Likert scale $(\alpha=0.74)$. The items were "local institutions," "regional institutions," "national government," "national health authorities," and "European Union."

\section{Data Analyses}

\section{Preliminary Analyses}

Since the dataset included some missing data, little's missing completely at random (MCAR) test was used to check whether they were completely at random-that is, whether the missingness pattern was completely unrelated to the considered variables [53] — before the implementation of further analyses. If this test provides non-significant results, the missing data are completely at random. The estimation technique for the subsequent analyses was selected based on the results from this test and following Newman's guidelines [53].

Given that all the measures but SoC-R were created ad hoc, exploratory factor analysis (EFA) with principal axis factoring and promax rotation was run for each of them. The sphericity was checked using Bartlett's test and the adequacy of sampling using the Kaiser-Meyer-Olkin (KMO) measure. Then, confirmatory factor analysis (CFA) was run with structural equation modeling (SEM) to test the factor structure for each measure and the expected one for SoC-R [52]. To evaluate the model fit, the comparative fit index (CFI), the Tucker-Lewis Index (TLI), the root-mean-square error of approximation (RMSEA), and its $90 \%$ confidence interval (CI) were observed each time [54]: for CFI and TLI, values equal to or greater than 0.90 and 0.95 reflect good or excellent fit indices; for RMSEA, values equal to or smaller than 0.06 and 0.08 reflect good or reasonable fit indices. The reliability of each measure was checked through Cronbach's alpha. To assess discriminant validity, we used the techniques called $\mathrm{CI}_{\mathrm{CFA}}$ (sys) proposed by Rönkkö and Cho [55]. First, we inspected the standardized factor solution of 
the CFA model that comprises all measures employed in the present study and that are evaluated for discriminant validity. Next, we inspected the upper limits for positive correlation and the lower limits of the $95 \%$ CIs of the estimated factor correlations and compare their values against the cutoffs proposed by Rönkkö and Cho [55]. According to their proposed classification and cutoffs, correlation pairs whose upper limit of the $\mathrm{CI}$ is less than 0.8 indicate that there is not any evidence of a discriminant validity problem. To evaluate convergent validity, correlations among latent factors were calculated.

\section{Hypotheses Testing}

All the hypotheses for the study were tested fitting a multiple mediation model using SEM. The effectiveness of the institutional response, personal costs, social costs, family norms, friends norms, and SoC-R were included as the associated variables with avoidant and preventative behaviors; fear and anxiety $(0=$ no; $1=$ yes $)$ were entered as mediators in the relationships between personal costs, social costs, and the two kinds of protective behaviors. Respondents' age and gender $(0=$ male; $1=$ female $)$ were included in the model as control variables.

To evaluate the model fit, CFI, TLI, RMSEA, and its $90 \%$ CI were observed [54]. Bootstrap estimation was used to test the significance of the results [56] with 10,000 samples, and the bias-corrected $95 \%$ CI was computed by determining the effects at the 2.5th and 97.5th percentiles; the indirect effects are significant when 0 is not included in the CI.

\section{Results}

The results from Little's MCAR test, chi-square $=82.795$, $d f=63, p=0.048$, suggested that the missing data-which were construct-level ones [53] —were not completely at random. Nevertheless, the percentage of respondents who were partial respondents (PRPR, Newman, 2014) was 0.01-that is, only 62 respondents out of 4045 were partial ones. Thus, full information maximum likelihood (FIML) was used as the estimation technique for the subsequent analyses, following Newman's guidelines [53]. Overall, only two respondents were excluded from the analyses since they had missing data on an independent variable - that is, they did not provide their age.

Table 1 reports the means, standard deviations, and correlations of the scales used in the analyses. Preventative and avoidant behaviors were strongly and positively correlated to all the other measures but anxiety (avoidant behaviors). Furthermore, all the considered measures were also strongly and positively correlated with each other with a few exceptions. In particular, the two measures concerning the affective responses to the COVID-19 pandemic, i.e., fear and anxiety, were not correlated with the perception of the effectiveness of the institutional response; further, fear was negatively associated with SoC-R and not correlated with friends norms and avoidant behaviors; anxiety was not correlated with SoC-R. Overall, as to the health-protective actions the participants reported fairly high levels of compliance with both preventative and avoidant behaviors; however, only a few of them disclosed they were experiencing fear (30.7\%)

Table 1 Summary of intercorrelations among study variables

\begin{tabular}{|c|c|c|c|c|c|c|c|c|c|c|c|}
\hline & $M$ & $S D$ & 1 & 2 & 3 & 4 & 5 & 6 & 7 & 8 & 9 \\
\hline $\begin{array}{l}\text { 1. Efficacy of the institutional } \\
\text { response to the pandemic }\end{array}$ & $3.23^{\mathrm{a}}$ & 0.67 & - & & & & & & & & \\
\hline 2. Social costs & $4.22^{\mathrm{a}}$ & 0.72 & $-.09 * * *$ & - & & & & & & & \\
\hline 3. Personal costs & $3.27^{\mathrm{a}}$ & 0.70 & -.01 & $.38 * * *$ & - & & & & & & \\
\hline 4. Fear & $.31^{\mathrm{b}}$ & 0.46 & .03 & $.08 * * *$ & $.51 * * *$ & - & & & & & \\
\hline 5. Anxiety & $.28^{\mathrm{b}}$ & 0.45 & -.02 & $.05^{*}$ & $.39 * * *$ & $.43 * * *$ & - & & & & \\
\hline 6. SoC-R & $3.65^{\mathrm{a}}$ & 0.70 & $.19 * * *$ & $.11 * * *$ & $.11^{* * *}$ & .04 & $-.07 * *$ & - & & & \\
\hline 7. Family norms & $4.53^{\mathrm{a}}$ & 0.66 & $.20 * * *$ & $.20 * * *$ & $.31 * * *$ & $.12 * * *$ & $.09 * * *$ & $.25 * * *$ & - & & \\
\hline 8. Friends norms & $4.11^{\mathrm{a}}$ & 0.78 & $.23 * * *$ & $.23 * * *$ & $.15^{* * *}$ & $.07 * *$ & .03 & $.26 * * *$ & $.58 * * *$ & - & \\
\hline 9. Avoidant protective behaviors & $4.65^{\mathrm{a}}$ & 0.50 & $.18 * * *$ & $.21 * * *$ & $.44 * * *$ & $.17 * * *$ & $.10 * * *$ & $.26 * * *$ & $.51 * * *$ & $.37 * * *$ & - \\
\hline 10. Preventative protective behaviors & $3.73^{\mathrm{a}}$ & 0.94 & $.10^{* * *}$ & $.13^{* * *}$ & $.36 * * *$ & $.14 * * *$ & .04 & $.26^{* * *}$ & $.31 * * *$ & $.23 * * *$ & $.57 * * *$ \\
\hline
\end{tabular}

$S o C-R$ sense of community responsibility, $M$ mean, $S D$ standard deviation

${ }^{\mathrm{a}} 1-5$ scale range

${ }^{\mathrm{b}}$ Fear and anxiety were coded 1 if the respondent had experienced them and 0 if she/he had not

$* p<.05$

$* * p<.01$

$* * * p<.001$ 
or anxiety $(28.2 \%)$ with reference to the pandemic at the time of data collection.

As regard to the results of the measurement model, the fit of the model was satisfactory, $\chi^{2}(450)=5044.262$, $p<0.001 ; \mathrm{TLI}=0.92 ; \mathrm{CFI}=0.93$; $\mathrm{RMSEA}=0.050,90 \%$ CI $(0.049,0.051)$. As shown in Table 2, the upper limits (or lower limits for negative correlations) of the $95 \%$ CIs of the estimated factor correlations did not exceed 0.8 . Therefore, according to the classification and cutoffs proposed by Rönkkö and Cho [55], we did not find any evidence of a discriminant validity problem.

Table 3 displays the standardized item loadings and composite reliabilities. Composite reliabilities values all exceeded 0.7 , and all item loadings exceeded 0.4.

The fit of the SEM analysis was satisfactory, $\chi^{2}$ $(517)=5901.191, p<0.001 ; \mathrm{TLI}=0.91 ; \mathrm{CFI}=0.92$; RMSEA $=0.051,90 \% \mathrm{CI}(0.050,0.052)$. The explained variance was $42.1 \%$ for protective avoidant behaviors and $23.5 \%$ for protective preventative behaviors. Path coefficients of the hypothesized model are illustrated in Fig. 2. Consistent with $\mathrm{H}_{1}$, the perception of personal costs was positively related to both preventative and avoidant behaviors; on the contrary, the perception of social costs was negatively related to preventative behaviors and had no association with avoidant ones. A partially similar pattern was detected as regards to the perception of the effectiveness of the institutional response that was positively related to avoidant but unrelated to preventative behaviors. Furthermore, contrary to the predictions of $\mathrm{H}_{1}$, fear and anxiety did relate with lower engagement in both protective and avoidant behaviors. As detailed by $\mathrm{H}_{3}$, SoC-R and family norms were positively associated with both preventative and avoidant behaviors. However, contrary to the predictions of our third hypothesis, friends norms were not significantly associated with preventative and avoidant behaviors.

Table 4 reports the indirect and total effects concerning the relationships between personal and social costs, negative affective responses (i.e., fear and anxiety), and protective behaviors (i.e., preventative and avoidant). Consistent with $\mathrm{H}_{2}$, personal costs and the compliance toward recommended preventative and avoidant behaviors were mediated by anxiety and fear engendered by the COVID-19. However, contrary to our expectations, when entered together in the regression equation, personal costs were negatively connected to both preventative and avoidant behaviors. In addition, as predicted by $\mathrm{H}_{2}$, the relationship between social costs and preventative behaviors was significantly and positively mediated by anxiety and fear experienced during the COVID-19 outbreak. These indirect effects were all significant but modest. Furthermore, contrary to the predictions of $\mathrm{H}_{2}$, the relationship between social costs and avoidant behaviors was not mediated by anxiety and fear provoked by the COVID-19. The main reason for this finding was that the total effect of the relationship between social costs and avoidant behaviors was not significant.

Finally, as far as demographic characteristics are concerned, age was negatively related to fear and anxiety and positively related to the compliance toward health recommended preventative and avoidant behaviors. Gender (women) was significantly related to fear, anxiety, and the compliance toward health-recommended preventative and avoidant behaviors.

\section{Discussion}

Linking with the existing literature and previous health research, this study aimed at examining the variables associated with voluntary engagement in COVID-19 healthprotective behaviors-e.g., preventative and avoidant—in a large sample of Italian citizens during the 2020 March-May outbreak of the pandemic. In particular, the focus of the present study was to integrate instrumental/self-interested and normative/community-based dimensions involved in the respect of mandatory public health orders.
Table 2 Upper limits (or lower limits for negative correlations) of the $95 \%$ CIs of the estimated factor correlations

\begin{tabular}{lllllllllll}
\hline & 1 & 2 & 3 & 4 & 5 & 6 & 7 & 8 & 9 & 10 \\
\hline $\begin{array}{l}\text { 1. Efficacy of the institutional } \\
\text { response to the pandemic }\end{array}$ & - & & & & & & & & \\
2. Social costs & -.13 & - & & & & & & & \\
3. Personal costs & -.05 & .41 & - & & & & & & \\
4. Fear & .08 & .13 & .55 & - & & & & & \\
5. Anxiety & -.07 & .10 & .43 & .48 & - & & & & \\
6. SoC-R & .23 & .14 & .15 & .08 & -.11 & - & & & \\
7. Family norms & .25 & .24 & .35 & .17 & .14 & .29 & - & & \\
8. Friends norms & .27 & .28 & .19 & .12 & .08 & .30 & .61 & - & & \\
9. Avoidant protective behaviors & .23 & .26 & .48 & .22 & .15 & .31 & .56 & .41 & - & \\
10. Preventative protective behaviors & .14 & .17 & .40 & .19 & .09 & .30 & .35 & .27 & .61 & - \\
\hline
\end{tabular}

$S o C-R$ sense of community responsibility 
Table 3 Standardized item loadings and composite reliabilities

\begin{tabular}{|c|c|}
\hline Factor/item & Values \\
\hline SoC-R & .90 \\
\hline Item 1 & .66 \\
\hline Item 2 & .72 \\
\hline Item 3 & .83 \\
\hline Item 4 & .77 \\
\hline Item 5 & .83 \\
\hline Item 6 & .78 \\
\hline Personal costs & .74 \\
\hline Item 1 & .69 \\
\hline Item 2 & .47 \\
\hline Item 3 & .41 \\
\hline Item 4 & .70 \\
\hline Item 5 & .72 \\
\hline Social costs & .85 \\
\hline Item 1 & .87 \\
\hline Item 2 & .85 \\
\hline Item 3 & .70 \\
\hline Preventative protective behaviors & .76 \\
\hline Item 1 & .74 \\
\hline Item 2 & .73 \\
\hline Item 3 & .68 \\
\hline Avoidant protective behaviors & .80 \\
\hline Item 1 & .57 \\
\hline Item 2 & .65 \\
\hline Item 3 & .60 \\
\hline Item 4 & .65 \\
\hline Item 5 & .66 \\
\hline Friends norms & - \\
\hline Item 1 & .89 \\
\hline Item 2 & .79 \\
\hline Family norms & - \\
\hline Item 1 & .91 \\
\hline Item 2 & .87 \\
\hline Efficacy of the institutional response to the pandemic & .76 \\
\hline Item 1 & .58 \\
\hline Item 2 & .61 \\
\hline Item 3 & .80 \\
\hline Item 4 & .51 \\
\hline Item 5 & .62 \\
\hline
\end{tabular}

The numbers reported in the same row with the scales are composite reliabilities, while item loadings are reported next to the items

$S o C-R$ sense of community responsibility

The primary general evidence of the study was that a partial support was found for the association between instrumental/self-interest and people's engagement in preventative and avoidant behaviors during the most severe stage of the coronavirus outburst $\left(\mathrm{H}_{1}\right)$. By contrast, almost all the normative/community-based variables were positively related to voluntary compliance with health-protective behaviors $\left(\mathrm{H}_{3}\right)$. Furthermore, the mediation findings-although the mediation effects were small—contributed to shed light on the involvement of the affective responses with cognitive factors as regards to the people compliance during emergency disease $\left(\mathrm{H}_{2}\right)$.

As far as it pertains to instrumental/self-interested variables, in line with prior investigations about health emergencies, the perceived risk of catching the virus and undergoing the damaging consequences of the pandemic on a personal basis was related to greater compliance with the prescribed behaviors $[14,16,45]$.

However, contrary to our expectations, the perceived impact from the societal consequences of the pandemic was not significantly related to avoidant behaviors [17] and even negatively associated with people's willingness to act preventative behaviors. The latter result contrasts with previous findings showing that worries about the crisis were significantly associated with people willingness to engage in health preventative behaviors (i.e., wearing a mask) [57].

We interpreted these unexpected findings in line with the conclusions raised by Probst, Lee and Bazzoli [58]. According to the authors, in the aftermath of the socio-economic burden of the COVID-19 pandemic, people may have experienced a cognitive overload and may have accessed fewer resources to well respond to the demands of the pandemic emergency thus failing in enacting the health-protective behaviors.

In addition, the perceived efficacy of health officials to halt the COVID-19 pandemic was found to vary with citizens' engagement in preventative but not in avoidant behaviors. These outcomes concurred with prior research about compliance. In fact, empirical results are somehow controversial as there is evidence that the perception of the adequacy of an institutional response is likely to predict public willingness to abide by health measures during the coronavirus pandemic [21], whereas earlier investigations did not find any significant relationship [46].

In addition, the relative inconsistency of the patterns of relationships among perceived social costs and the protective behaviors shed light on the differences in the types of preventative and avoidant conducts carried out in response to the COVID-19 pandemic. The results suggest that other variables are likely to account for the relationship between the instrumental dimensions investigated in this study and citizens' compliance with health prescriptions.

In contrast with results reported in prior literature [16, 43], in this study, fear and anxiety engendered by the coronavirus situation were linked to individuals being more prone to disengage from health-protective behaviors $[69,70]$. This seems to support that anxiety and fear per se do not serve functional and adaptive purposes [19]. However, looking at the mediation effects, these research findings revealed that fear and anxiety reversed the sign of the direct relationships. 


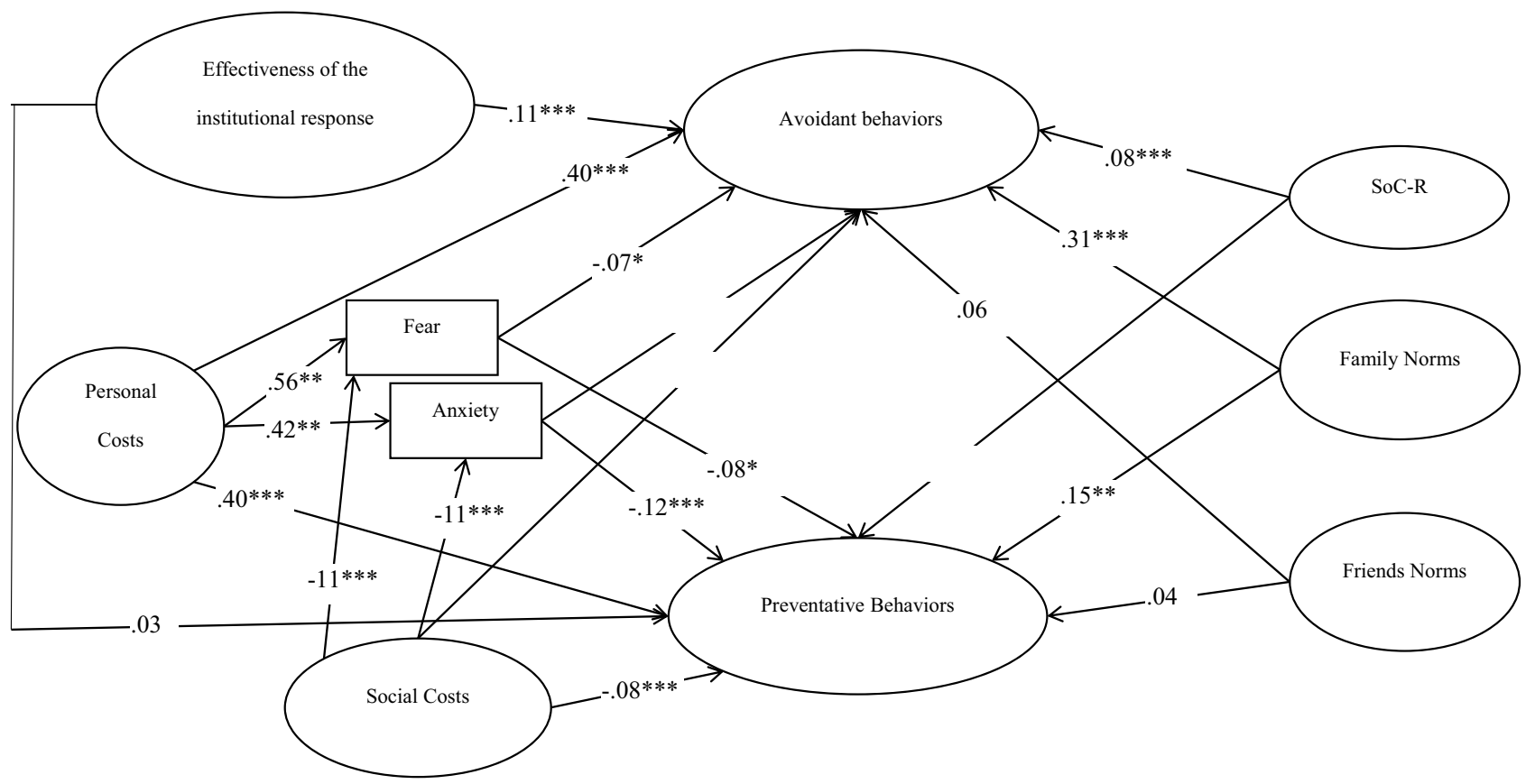

Instrumental/Self-Interested

Normative/Community-basedPerspective

Fig. 2 Path coefficients (structural equation model) from the hypothesized model of instrumental/self-interested and normative/communitybased predictors of avoidant and protective preventative behaviors during the COVID-19

In particular, in contrast with previous studies [15, 44, 45], Italian citizens who identified the pandemic situation as a serious risk to themselves were also less prone to abide by health-recommended measures through the partial mediation of anxiety and fear. As suggested by the extended parallel process model $[59,60]$, it is possible that, when worries about personal health are great and people feel unprepared to deal with the burdensome health emergency, negative emotions may instigate denying or defensive responses and inhibit the engagement in self-protective actions [24, 61].
Table 4 Indirect and total effects concerning the relationships among worries, emotions, and preventative behaviors

\begin{tabular}{llll}
\hline Paths & $\beta$ & $B(S E)$ & $B C$ 95\% CI \\
\hline Indirect effects & & & \\
Personal costs $\rightarrow$ fear $\rightarrow$ avoidant behaviors & $-.04^{*}$ & $-0.03^{*}(0.02)$ & {$[-0.07,-0.001]$} \\
Personal costs $\rightarrow$ anxiety $\rightarrow$ avoidant behaviors & $-.03^{*}$ & $-0.02^{*}(0.01)$ & {$[-0.05,-0.001]$} \\
Personal costs $\rightarrow$ fear $\rightarrow$ preventative behaviors & $-.04^{*}$ & $-0.05^{*}(0.02)$ & {$[-0.10,-0.005]$} \\
Personal costs $\rightarrow$ anxiety $\rightarrow$ preventative behaviors & $-.05^{* * *}$ & $-0.06^{* * *}(0.02)$ & {$[-0.10,-0.03]$} \\
Social costs $\rightarrow$ fear $\rightarrow$ avoidant behaviors & .01 & $0.004(0.002)$ & {$[0,0.01]$} \\
Social costs $\rightarrow$ anxiety $\rightarrow$ avoidant behaviors & .007 & $0.003(0.002)$ & {$[0,0.008]$} \\
Social costs $\rightarrow$ fear $\rightarrow$ preventative behaviors & $.01^{*}$ & $0.006^{*}(0.003)$ & {$[0.001,0.01]$} \\
Social costs $\rightarrow$ anxiety $\rightarrow$ preventative behaviors & $.01^{* *}$ & $0.008^{* *}(0.003)$ & {$[0.003,0.02]$} \\
Total effects & & & \\
Personal costs $\rightarrow$ avoidant behaviors & $.33^{* * *}$ & $0.27^{* * *}(0.03)$ & {$[0.21,0.33]$} \\
Personal costs $\rightarrow$ preventative behaviors & $.31^{* * *}$ & $0.37^{* * *}(0.04)$ & {$[0.30,0.45]$} \\
Social costs $\rightarrow$ avoidant behaviors & -.02 & $-0.01(0.01)$ & {$[-0.03,0.01]$} \\
Social costs $\rightarrow$ preventative behaviors & $-.06^{* *}$ & $-0.04 * *(0.02)$ & {$[-0.07,-0.01]$} \\
\hline
\end{tabular}

Fear and anxiety were coded 1 if the respondent had experienced them and 0 if she/he had not $S E$ standard error, $B C$ bias-corrected, $C I$ confidence interval

$* p<.05$ (2-tailed)

$* * p<.01$ (2-tailed)

$* * * p<.001$ (2-tailed) 
Speculatively, this could happen if people do not believe that they can cope effectively with the coronavirus crisis. Furthermore, these findings dovetail with prior research [5] that showed how negative affective responses stemmed out from the perceived risk of suffering the coronavirus were associated with engagement in COVID-19 related risk behaviors, such as having houseguests and shopping.

Conversely, as far as it pertains to social issues, the results unveiled that, when people are concerned with the negative impact of the epidemics at the societal level, they are also more likely to engage in behavioral change in case of negative emotional reactions. All over the world, during the first wave of the pandemic, the situation of the coronavirus spread has increased levels of anxiety and fear amongst individuals with the concomitant negative impact of the disease on economy and workforce [62]. Whereas the scarcity of cognitive resources may have accounted for the fact that insecure people were less prone to engage in health-protective behaviors under socio-economic stressful situations [58], negative emotions may have served as normative and protective resources helping people to effectively deal with the demands engendered by the lockdown measures. Indeed, it may be the case that people may believe that the responsibility for dealing with the socio-economic consequences of the pandemic does not depend on their own but rests on the sum of citizens' behaviors and institutional measures. Hence, individuals may have not felt self-isolated against the epidemic, and fear and anxiety may have functioned like personal engagement and served adaptive purposes [16]. As for the role of covariates, the research findings were consistent with extant literature indicating that young people and women were at higher psychological risk of experiencing negative emotions than elderly and men [63].

The expected pattern of association was found for the normative/community-based factors with the only exception of friends norms. Consistent with prior studies, individuals' perception of their family as prescribing compliance with health measures was associated with their decisions to undertake preventative and avoidant conducts [32,33]. On the contrary, the result concerning friends' norms confirms what is by now well-known about the important role of the family in the construction of norms and as a mediator between individuals and their socio-cultural context [64]. Moreover, as the data were collected when Italy was in complete lockdown, family may have represented the only proximate normative environment where people formed their views of health behaviors. In addition, SoC-R appeared a good correlate of compliance with health-protective behaviors, corroborating that commitment to community and willingness to support it were linked to Italian citizens will to change their behavioral habits and abide by COVID-19 restrictions [35, 37, 38].

\section{Conclusion, Limitations, and Implications for Interventions}

Strict compliance with recommended health-protective measures is crucial to slow down the spread of the virus since day 1 of the COVID-19 pandemic. Our study offers four major contributions to understanding how to endure public compliance. First, the research findings corroborated that compliance with formal rules is a multimodal phenomenon, and integrating instrumental/self-interest and normative/community-based variables can offer a more careful account of people's decision to abide by the institutional measures. Second, they show that risk perception is a key associate of health-protective behavior, but such an association varies whether the cognitive evaluation of the threat refers to either personal or societal issues. Third, the findings corroborated that people's decision to engage in health-protective behaviors is not only cognitively but also emotionally salient. However, this interaction does not necessarily encourage normative behaviors but rather has different relations with whether people are concerned with personal or societal issues. Fourth, preventative and avoidant behaviors are anything but the same; they are associated with different patterns of relationships with the instrumental and normative variables considered in this study.

There are limitations in our study that have to be acknowledged. First, a major limitation concerns the cross-sectional nature of the research design that prevents from inferring causal relationships among the variables. Second, our study relied on a convenient sample of participants so as findings cannot be generalized to the overall Italian population. Third, it is possible that participants' reports on their behaviors may have been affected by social desirability. A fourth limitation is related to the low percentage of explained variance of preventative protective behaviors suggesting that future studies may consider other variables. Fifth, the use of a dichotomous single-item for measuring negative emotions may have not accurately captured the participants' subjective emotional states.

Notwithstanding these limitations, this study highlights some remarkable points with interesting implications for intervention and future research development. As far as it concerns instrumental/self-interest variables, the pattern of results was relatively incongruous across preventative and avoidant health behaviors. Whereas preventative behaviors required citizens to adjust their daily routine, avoidant behaviors obliged them to radically change their social and relational life cutting off interpersonal interactions and contacts as well as restricting their movements. Indeed, communication campaigns to enforce adherence to the prescribed measures should be targeted and provide people with information that is clear, consistent, and, above all, action-focused. 
Besides, to our knowledge, the majority of prior research about compliant behavior during health emergencies investigated emotional factors as responses to the perceived risks for personal health, whereas this study assessed how the negative emotions experienced during the pandemic combined with risk perception and behavioral decisions. Our findings indicate that, when facing an unexpected lifethreatening event, fear and anxiety can be associated with maladaptive, self-defeating actions; future investigations are needed to examine what can mitigate negative emotions while strengthening health-protective behaviors. However, considering that the mediation effects proved to be not so strong, it may be the case to notice that, in the aftermath of the COVID-19 pandemic, that break out as an unprecedent public health emergency with tremendous psychological impacts, affective responses may have influenced the cognitive evaluations of self-related risks, rather than being impacted by them. Further evidence would be needed to address this point. In addition, given that the present study only tackled the presence or absence of anxiety and fear but provided no pieces of information about their levels further research are needed to see whether these emotions could have different relations with individual behaviors according to their levels. Furthermore, these results suggest that institutional communication should provide for clear and unambiguous messages making people aware of the benefits of the health-protective behaviors hence contributing to their adoption, as this could reduce uncertainty and enhance perceived self-efficacy.

Finally, the findings also indicate that citizens' voluntary compliance with authority prescriptions is not only secured by the prospect risk of suffering costs in case of violations but also stems from personal commitment to valued groups $[65,66]$. With concerns to this, this study represents an original contribution as it points how a shared sense of community is effectively linked with adherence to recommended behaviors. Indeed, it may be argued that the effective enactment of behavioral changes can be sustained by targeting the recommendations not only on risk minimization for oneself but also on the allocation of personal responsibility toward the belonging community. For this reason, interventions and public health communication delivering social norms-based messaging may be ineffective if people do not cultivate a sense of belonging and responsibility toward the community. However, more research is needed to advance knowledge. Our study represents the first step in this direction.

\section{Declarations}

Ethical Approval All procedures performed in studies involving human participants were in accordance with the ethical standards of the institutional and/or national research committee and with the 1964 Helsinki declaration and its later amendments or comparable ethical standards.
Informed Consent Informed consent was obtained from all individual participants included in the study.

Conflict of Interest The authors declare no competing interests.

\section{References}

1. World Health Organization. Novel Coronavirus (2019-nCoV) Situation Report - 12; 2020.

2. West R, Michie S, Rubin GJ, Amlôt R. Applying principles of behaviour change to reduce SARS-CoV-2 transmission. Nat Hum Behav. 2020;4(5):451-9.

3. World Health Organization. Coronavirus disease (COVID-19) advice for the public. 2020 April 29; 2020.

4. Bish A, Michie S. Demographic and attitudinal determinants of protective behaviours during a pandemic: a review. Br J Health Psychol. 2010;15(4):797-824.

5. Alegria KE, Fleszar-Pavlović SE, Ngo DD, et al. The role of risk perceptions and affective consequences in COVID-19 protective behaviors. Int J Behav Med. 2021;28(6):801-7.

6. Pratt TC, Cullen FT, Blevins KR, Daigle LE, Madensen TD. The empirical status of deterrence theory: a meta-analysis. In: Cullen FT, Wright JP, Blevins KR, editors. Taking Stock: The Status of Criminological Theory. New Bronswick, NJ, US: Transaction Publisher; 2006. p. 367-96.

7. Murphy K, Williamson H, Sargeant E, McCarthy M. Why people comply with COVID-19 social distancing restrictions: self-interest or duty? Australian \& New Zealand J Criminol. 2020;0(0):0004865820954484.

8. Nagin DS. Deterrence in the twenty-first century. Crime Justice. 2013;42:199-263.

9. Kuo K-M, Talley PC, Huang C-H. A meta-analysis of the deterrence theory in security-compliant and security-risk behaviors. Comp Sec. 2020;96:101928.

10. Piquero AR, Paternoster R, Pogarsky G, Loughran T. Elaborating the individual difference component in deterrence theory. Annual Rev Law Soc Sci. 2011;7(1):335-60.

11. Pogarsky G. Identifying, "deterrable" offenders: implications for research on deterrence. Justice Q. 2002;19(3):431-52.

12. Tang CS-k, Wong C-y. An outbreak of the severe acute respiratory syndrome: predictors of health behaviors and effect of community prevention measures in Hong Kong, China. Am J Public Health. 2003;93(11):1887-1888.

13. Leung GM, Quah S, Ho L-M, et al. A tale of two cities: community psychobehavioral surveillance and related impact on outbreak control in Hong Kong and Singapore during the severe acute respiratory syndrome epidemic. Infect Control Hosp Epidemiol. 2015;25(12):1033-41.

14. Jones JH, Salathé M. Early assessment of anxiety and behavioral response to novel swine-origin influenza $\mathrm{A}(\mathrm{H} 1 \mathrm{~N} 1)$. PLoS One. 2009;4(12):e8032.

15. Rubin GJ, Amlôt R, Page L, Wessely S. Public perceptions, anxiety, and behaviour change in relation to the swine flu outbreak: cross-sectional telephone survey. BMJ. 2009;339:b2651.

16. Harper CA, Satchell LP, Fido D, Latzman RD. Functional fear predicts public health compliance in the COVID-19 pandemic. Int J Ment Heal Addict. 2020:1-14.

17. Wise T, Zbozinek TD, Michelini G, Hagan CC, Mobbs D. Changes in risk perception and self-reported protective behaviour during the first week of the COVID-19 pandemic in the United States. Royal Soc Open Sci. 2020;7(9):200742.

18. Plohl N, Musil B. Modeling compliance with COVID-19 prevention guidelines: the critical role of trust in science. Psychol Health Med. 2020:1-12. 
19. Vally Z. Public perceptions, anxiety and the perceived efficacy of health-protective behaviours to mitigate the spread of the SARSCov-2/ COVID-19 pandemic. Public Health. 2020;187:67-73.

20. Murphy K, Williamson H, Sargeant E, McCarthy M. The attitudes to authority during COVID-19 survey: Griffith Criminology Institute, Griffith University2020.

21. Clark C, Davila A, Regis M, Kraus S. Predictors of COVID-19 voluntary compliance behaviors: an international investigation. Global Transitions. 2020;2:76-82.

22. Vinck P, Pham PN, Bindu KK, Bedford J, Nilles EJ. Institutional trust and misinformation in the response to the 2018-19 Ebola outbreak in North Kivu, DR Congo: a population-based survey. Lancet Infect Dis. 2019;19(5):529-36.

23. Siegrist M, Zingg A. The role of public trust during pandemics: implications for crisis communication. Eur Psychol. 2014;19(1):23-32.

24. Van Bavel JJ, Baicker K, Boggio PS, et al. Using social and behavioural science to support COVID-19 pandemic response. Nat Hum Behav. 2020;4(5):460-71.

25. Tyler TR, Blader SL. Cooperation in groups: procedural justice, social identity, and behavioral engagement. Philadelphia, PA, USA: Psychology Press; 2000.

26. Ajzen I. From intentions to actions: a theory of planned behavior. In: Kuhl J, Beckmann J, editors. Action control: from cognition to behavior. New York: Springer-Verlag; 1985. p. 11-39.

27. Ajzen I, Albarracin D. Predicting and changing behavior: a reasoned action approach. In: Ajzen I, Albarracin D, Hornik R, editors. Prediction and Change of Health Behavior: Applying the reasoned action approach. Mahwah, NJ, US/London: Lawrence Erlbaum Associates Publishers; 2007. p. 3-21.

28. Drury J, Alfadhli K. Shared social identity in emergencies, disasters and conflicts. In: Haslam C, Bhui KS, Williams R, Haslam SA, Bailey S, Kemp V, editors. Social scaffolding: applying the lessons of contemporary social science to health and healthcare. Cambridge: Cambridge University Press; 2019. p. 154-64.

29. Blader SL, Tyler TR. Testing and extending the group engagement model: Linkages between social identity, procedural justice, economic outcomes, and extrarole behavior. J Appl Psychol. 2009;94(2):445-64.

30. Reicher S, Stott C. On order and disorder during the COVID-19 pandemic. Br J Soc Psychol. 2020;59(3):694-702.

31. Tang CS-k, Wong C-y. Factors influencing the wearing of facemasks to prevent the severe acute respiratory syndrome among adult Chinese in Hong Kong. Prevent Med. 2004;39(6):1187-1193.

32. Farias JEM, Pilati R. Violating social distancing amid the COVID19 pandemic: psychological factors to improve compliance. 2020.

33. Goldberg M, Gustafson A, Maibach E, et al. Social norms motivate COVID-19 preventative behaviors. PsyArXiv. 2020.

34. Sarason SB. The psychological sense of community: prospects for a community psychology. London: Jossey-Bass; 1974.

35. Nowell B, Boyd N. Viewing community as responsibility as well as resource: deconstructing the theoretical roots of psychological sense of community. J Community Psychol. 2010;38(7):828-41.

36. Procentese F, Gatti F, Falanga A. Sense of responsible togetherness, sense of community and participation: Looking at the relationships in a university campus. Hum Aff. 2019;29(2):247-63.

37. Nowell B, Boyd NM. Sense of community responsibility in community collaboratives: advancing a theory of community as resource and responsibility. Am J Community Psychol. 2014;54(3-4):229-42.

38. Boyd NM, Martin EC. Sense of community responsibility at the forefront of crisis management. Administrative Theory \& Praxis. 2020:1-13.

39. Mihashi M, Otsubo Y, Yinjuan X, Nagatomi K, Hoshiko M, Ishitake T. Predictive factors of psychological disorder development during recovery following SARS outbreak. Health Psychol. 2009;28(1):91-100.

40. Taylor S. The psychology of pandemics: preparing for the next global outbreak of infectious disease: Cambridge Scholars Publishing; 2019.

41. Brooks SK, Webster RK, Smith LE, et al. The psychological impact of quarantine and how to reduce it: rapid review of the evidence. The Lancet. 2020;395(10227):912-20.

42. Pakpour AH, Griffiths MD. The fear of COVID-19 and its role in preventive behaviors. Journal of Concurrent Disorders. 2020;2(1):58-63.

43. Brouard S, Vasilopoulos P, Becher M. Sociodemographic and Psychological correlates of compliance with the COVID-19 public health measures in France. Can J Polit Sci. 2020;53(2):253-8.

44. Lau JTF, Yang X, Tsui H, Kim JH. Monitoring community responses to the SARS epidemic in Hong Kong: from day 10 to day 62. J Epidemiol Community Health. 2003;57(11):864-70.

45. Leung GM, Ho L-M, Chan SKK, et al. Longitudinal assessment of community psychobehavioral responses during and after the 2003 outbreak of severe acute respiratory syndrome in Hong Kong. Clin Infect Dis. 2005;40(12):1713-20.

46. Prati G, Pietrantoni L, Zani B. A social-cognitive model of pandemic influenza H1N1 risk perception and recommended behAviors in Italy. Risk Anal. 2011;31(4):645-56.

47. Zickfeld JH, Schubert TW, Herting AK, Grahe J, Faasse K. Correlates of health-protective behavior during the initial days of the COVID-19 outbreak in Norway. Front Psychol. 2020;11(2671).

48. Mertens G, Gerritsen L, Duijndam S, Salemink E, Engelhard IM. Fear of the coronavirus (COVID-19): predictors in an online study conducted in March 2020. J Anxiety Disord. 2020;74:102258.

49. Raude J, Debin M, Souty C, et al. Are people excessively pessimistic about the risk of coronavirus infection? PsyArXiv. 2020.

50. Cypryańska M, Nezlek JB. Anxiety as a mediator of relationships between perceptions of the threat of COVID-19 and coping behaviors during the onset of the pandemic in Poland. PLoS One. 2020;15(10):e0241464.

51. Ministero della Salute. Some simple recommendations to contain the coronavirus infection; 202021 November 2020.

52. Prati G, Procentese F, Albanesi C, et al. Psychometric properties of the Italian version of the sense of community responsibility scale. J Community Psychol. 2020;48(6):1770-90.

53. Newman DA. Missing data: five practical guidelines. Organ Res Methods. 2014;17(4):372-411.

54. MacCallum RC, Austin JT. Applications of structural equation modeling in psychological research. Annu Rev Psychol. 2000;51(1):201-26.

55. Rönkkö M, Cho E. An updated guideline for assessing discriminant validity. Org Res Methods. 2020:1094428120968614.

56. Hayes AF. Introduction to mediation, moderation, and conditional process analysis: a regression-based perspective. New York, NY: The Guilford Press; 2018.

57. Rieger M. To wear or not to wear? Factors influencing wearing face masks in Germany during the COVID-19 pandemic. Social Health and Behavior. 2020;3(2):50-4.

58. Probst TM, Lee HJ, Bazzoli A. Economic stressors and the enactment of CDC-recommended COVID-19 prevention behaviors: the impact of state-level context. J Appl Psychol. 2020;105(12):1397-407.

59. McMahan S, Witte K, Meyer Ja. The perception of risk messages regarding electromagnetic fields: extending the extended parallel process model to an unknown risk. Health Commun. 1998;10(3):247-259.

60. Witte K. Putting the fear back into fear appeals: the extended parallel process model. Commun Monogr. 1992;59(4):329-49.

61. Shirahmadi S, Seyedzadeh-Sabounchi S, Khazaei S, et al. Fear control and danger control amid COVID-19 dental crisis: 
application of the extended parallel process model. PLoS One. 2020;15(8):e0237490.

62. Rajabimajd N, Alimoradi Z, Griffiths M. Impact of COVID19-related fear and anxiety on job attributes: a systematic review. Asian Journal of Social Health and Behavior. 2021;4(2):51-5.

63. Nathiya D, Singh P, Suman S, Raj P, Tomar B. Mental health problems and impact on youth minds during the COVID-19 outbreak: cross-sectional (RED-COVID) survey. Social Health and Behavior. 2020;3(3):83-8.

64. McGoldrick M, Heiman B, Carter AE. The changing family life cycle. a perspective on normalcy. In: Walsh F, editor. Normal family processes. New York, NY: Guilford; 1993. pp. 405-443.

65. Tyler TR, Darley J. Building a law-abiding society: taking public views about morality and the legitimacy of legal authorities into account when formulating substantive law. Hofstra Law Review. 2000;28:5.

66. Drury J. The role of social identity processes in mass emergency behaviour: an integrative review. Eur Rev Soc Psychol. 2018;29(1):38-81.
67. Giner-Sorolla R. Is affective material in attitudes more accessible than cognitive material? The moderating role of attitude basis. Eur J Soc Psychol. 2004;34:761-80.

68. Giner-Sorolla R. Affective attitudes are not always faster: the moderating role of extremity. Pers Soc Psychol Bull. 2001;27:666-77.

69. Chang KC, Strong C, Pakpour AH, et al. Factors related to preventive COVID-19 infection behaviors among people with mental illness. J Formos Med Assoc. 2020;119(12):1772-80.

70. Chang KC, Hou WL, Pakpour AH, et al. Psychometric testing of three COVID-19-related scales among people with mental illness. Int J Ment Heal Addict. 2020:1-13.

71. Compare C, Prati G, Guarino A, et al. Predictors of prosocial behavior during the COVID-19 national lockdown in Italy: testing the role of psychological sense of community and other community assets. Community Psychology in Global Perspective. 2021;7(2):22-38.

Publisher's Note Springer Nature remains neutral with regard to jurisdictional claims in published maps and institutional affiliations. 